\title{
The Significance of Glass Transition Temperature in Processing of Selected Fried Food Products: A Review
}

\author{
K.A. Abbas (Corresponding author) \\ Department of Food Technology, Faculty of Food Science and Technology, Universiti Putra Malaysia \\ 43400 Serdang, Selangor, Malaysia \\ Tel: 60-3-8946-8534 E-mail: ali_kassim@hotmail.com
}

Ola Lasekan

Department of Food Technology, Faculty of Food Science and Technology, Universiti Putra Malaysia

43400 Serdang, Selangor, Malaysia

Tel: 60-3-8946-8535 E-mail: Lasekan@food.upm.edu.my

Sahar K. Khalil

Faculty of political Sciences, University of Al-nahrain, Iraq

Tel: 96-4-770-8739-943 E-mail: ali_kassim@hotmail.com

\begin{abstract}
This paper emphasized the significance of the glass transition temperature ( $\mathrm{Tg}$ ) by highliting its applications in drying (hot air and freeze drying) for various food systems such as skim milk powders, rice kernels, starch and sugar products and some freeze-dried products such as strawberries and surimi. The study revealed that the major components of the specified foods (which consist of mixture of ingredients), for example lactose in skim milk powder and sucrose in sugar mixtures, will influence the glass transition temperature of the food. Moreover, $\mathrm{Tg}$ is an important parameters for determining the optimum processing conditions of dried products. Thus, it is used in designing drying equipment to meet the purpose. In general, Tg affects the physical properties of food such as stickiness, caking and agglomeration. The effect of moisture content on Tg was covered by almost all studies focusing on Tg of foods. Meanwhile, the effect of pressure on Tg was not well covered due to its scarce availability in the existing literature. In term of test methods for determining the Tg of foods, it seems that not all test methods are suitable for certain type of foods, accordingly, more study on the recommended test methods should be carried out.
\end{abstract}

Keywords: Glass transition temperature, Applications, Hot air and freeze drying

\section{Introduction}

Glass transition temperature, $\mathrm{Tg}$, can be defined as the temperature at which an amorphous system changes from the glassy to the rubbery state. In some areas it has been used as indicator of food stability and to predict the behavior of foodstuffs. Glass transition theory from the study of polymer science may help to understand textural properties of food systems and explain changes which occur during food processing and storage such as stickiness, caking, softening and hardening. In drying of food products, glass transition temperature is one of the crucial factors that need to be considered seriously (Ted-Labuza et al., 2004; Ratti, 2001; Stefan Kasapis, 2006).

Figure 1 shows a simple glass rubber transition diagram of an amorphous material, the line representing the glass temperature, $\mathrm{Tg}$. The glass transition -point is the temperature $(\mathrm{Tg})$ at a given moisture content where a transition from a glassy stable amorphous solid state to a rubbery amorphous solid state can begin to take place. As seen in Figure 1 this can take place by either increasing the temperature or increasing the plasticizer amount (e.g. water in foods) or both. In the amorphous state of a solid, the molecules are randomly distributed and mobile while in a crystal the molecules are in a distinct arrangement with little mobility. The glassy state which is below the $\mathrm{Tg}$ line has brittle like properties similar to stiff hard plastics, glass wool or a crisp cracker. In the rubbery state above the $\mathrm{Tg}$ line at constant temperature and thus increasing relative humidity, the material can pick up water and collapse (flow) under the force of gravity (Ted Labuza et al., 2004). 
Figure 2 shows the glass transition (Tg) curve of an appropriate solid component entered onto the equilibrium diagram to illustrate the points of transition between the two solid amorphous non-equilibrium states of matter, i.e. rubbery or glassy. This is termed the state diagram and can be used to illustrate some physical state changes of foods as a function of moisture content (or plasticizer) during any water removal processes such as drying, baking, extrusion, evaporation as well as in storage. The state diagram defines the moisture content and temperature region at which a food/ingredient domain is glassy, rubbery, crystalline solute, frozen, etc (Ted Labuza et al., 2004).

Regarding the applications of $\mathrm{Tg}$ in food industry, many published works have been noted in the literature, but no comprehensive research summarizing the current status as well as the latest developments for the last decade is available to guide the food process designers in this regard.

In the light of above, this review work has been justified.

Before discussing further on this topic, it would be appropriate to understand the commonly used drying processes in the production of amorphous food products, i.e. hot air and freeze drying.

\section{Hot air and freeze drying}

The term drying refers generally to the removal of moisture from a substance to a minimum level where no microorganism can survive. It is the mainly widespread and most energy-consuming food preservation process. Various drying methods have been discovered for various types of foods. Ratti (2001), reported conventional drying offers dehydrated products that can have an extended shelf life but the quality of the dried product is drastically reduced from the original foodstuff. On the other hand, freeze drying which is based on the dehydration by sublimation of a frozen product, gives better quality dried products due to the fact that deterioration and microbiological reactions are stopped in the absence of liquid water and low temperatures processing. He mentioned that researches on effect of drying and freeze drying were normally emphasized on three parameters which are colour, volume and rehydration.

Freeze-drying process is not widely used in the food industry due to its high operation cost (Ratti, 2001). Thus, from the literature search more studies on glass transition temperature were carried out on products produced by hot-air drying as compared to freeze-drying.

The products which will be covered in this report include those which are produced via hot-air drying (skim milk powders, rice kernels and starch and sucrose products) and freeze drying (strawberries and surimi products).

\section{Skim milk powders}

Spray drying (or hot air drying) is the most common method of dehydrating milk and milk products. It involves rapid removal of moisture leading to the formation of amorphous lactose which forms a continuous matrix in which proteins, fat globules, and air cells disperse (Shresta et al., 2007).

Drying profile and glass transition temperature of milk and milk products vary depending on its compositions. Shresta, et al. (2007), has studied the effect of protein concentration on the glass transition temperature of spray-dried skim milk powders and he concluded that $\mathrm{Tg}$ of the powders sorbed at different humidities and showed no distinct change in $\mathrm{Tg}$ values, indicating the dominant effect of lactose on the glass transition temperature of skim milk powders. The major ingredient in milk powder is lactose which has a relatively high $\mathrm{Tg}$ of $97-116^{\circ} \mathrm{C}$. Thus, many studies were carried out to understand the behavior of lactose during drying which contributed to the quality and drying performance of skim milk powders.

Meanwhile, Langrish (2008) has reported that the process of amorphous lactose inside spray dryers can be split into at least two stages. The two stages include, firstly, the process of solid-phase crystallization, and secondly, the possibility of crystallization in the liquid phase as the liquid droplets dry out, and the solids concentration and saturation levels inside them increase.

Figure 3 illustrates the crystallization process in solid lactose as an activated rate process allows the concept of a reverse reaction from the crystalline to the amorphous form once there is sufficient activation energy. This reverse reaction in the impact of crystalline lactose on walls, where the surfaces of lactose become heated, transforming the surface material back into an amorphous form that is sticky. Langrish (2008), suggested an extension to this figure 3 , because not only is the process of crystallization from the rubbery state is likely to be affected $(\mathrm{f}(\mathrm{T}, \mathrm{t}))$ by the temperature $(\mathrm{T})$ and time $(\mathrm{t})$, but the process is also likely to be affected by the material moisture content, which in turn will be affected by the time scales for transformation forwards and backwards from the crystalline and amorphous state. 
According to Langrish (2008), stickiness of spray dried lactose occurs at 10-20 K above the glass transition temperature, contributing to increase of viscosity at these temperatures, as shown in Figure 4 which illustrated the sorption experiments on spray dried-lactose as compared to calculated values.

Amorphous lactose and other sugars (if present) in milk powders can undergo a glassy-to-rubbery transition when held at a temperature higher than their glass transition temperature (Tg). Amorphous sugar particles are highly hygroscopic and will absorb water at higher humidity resulting in plasticization that lowers the $\mathrm{Tg}$ of the particles significantly. The molecular mobility increases when viscosity decreases and that occur once the product temperature is around or more than its glass transition temperature. These phenomena trigger a chain of events leading to stickiness, caking and crystallization. Stickiness of dairy powder results in poor product quality, lower yield during drying, operation problems and difficulties in handling and storage (Shrestha et al., 2007).

Fitzpatrick, et al. (2007), had reported the relationship between the glass transition temperature, flowability and caking of powders containing amorphous lactose. He concluded that exposing milk powder to over $10-20{ }^{\circ} \mathrm{C}$ above the lactose glass transition makes the powder more sticky, rendering it a lot more cohesive and also increases its adhesion to a stainless steel surface (as shown in Figure 5). This glass transition induced stickiness is time-dependent. Over time, crystallisation can occur converting the amorphous lactose into crystalline lactose. Furthermore, the caking behaviour of powders depends on the amount of component present in the amorphous state.

Figure 6 illustrates the thermograms of skim milk powders exposed to $76 \% \mathrm{RH}$ at $20^{\circ} \mathrm{C}$ for certain times. At $0 \mathrm{~h}$, there was a distinct glass transition, with glass transition temperatures of around $46{ }^{\circ} \mathrm{C}$ for skim milk powder (SMP). After 6-hours and 12-hours exposure time, the Tg for SMP was reduced to $5{ }^{\circ} \mathrm{C}$. It take between 24 to $48 \mathrm{~h}$ for the glass transition to vanish. Consequently, the caking of SMP may result from the formation of liquid bridges between the powder particles, which binds particles together to form a cake. also, as powder components dissolve in water, the liquid bridges will contain these components, which increases the viscosity of the liquid bridges making them stickier and forming a stronger cake. As water or thermal plasticization becomes excessive, lactose molecules form nuclei and crystallised randomly to various crystalline forms. As crystallisation proceeds sorbed water is lost, as the crystallised lactose is a lot less hygroscopic, and this leads to a reduction in liquid bridging which will influence cake strength (Fitzpatrick, et al., 2007).

Fitzpatrick, et al., (2007), also reported that the water content of milk powder increased significantly with greater exposure time and relative humidity, as illustrated in Table 1. The positive temperature difference between the powder exposure temperature minus the glass transition temperature $[\mathrm{T}-\mathrm{Tg}]^{+}$was calculated (if this was negative, it was assigned a zero value). Table 1 shows how $[\mathrm{T}-\mathrm{Tg}]^{+}$varies for the different experimental conditions. It can be seen from these data values that if $[\mathrm{T}-\mathrm{Tg}]^{+}$was 0 or less than $10^{\circ} \mathrm{C}$, then the cake strength was small or negligible, however, if $[\mathrm{T}-\mathrm{Tg}]^{+}$was greater than $20^{\circ} \mathrm{C}$, then cake strength increased to greater than $1 \mathrm{~N}$. Accordingly it can be inferred that the lactose glass transition was affecting the initial development of cake strength.

Shrestha, et al. (2007), concluded that spray drying of skim milk powder containing hydrolysed lactose (SMPHL) resulted in very low cyclone recovery of $25 \%$ and a large amount of powder remained stuck inside the spray dryer. The equilibrium moisture content of SMPHL was lower than that of lactose for each range of water activity when humidified for 21 days at $23{ }^{\circ} \mathrm{C}$ using saturated salt solutions. The Tg of anhydrous SMPHL was $49^{\circ} \mathrm{C}$.

Shrestha, et al. (2007), expected the Tg values to decreased with increase in storage $\mathrm{a}_{\mathrm{w}}$ or moisture content due to plasticizing effect of water on the amorphous components as shown by his findings in Figure 7 . The critical water activity and moisture content for SMPHL were 0.15 and $2.4 \mathrm{~g} / 100 \mathrm{~g}$ dry solid, respectively. In comparison, pure lactose stored under similar conditions had critical aw of 0.39 and water content of $8 \mathrm{~g} \mathrm{H}_{2} \mathrm{O} / 100 \mathrm{~g}$ dry solid. The lower critical aw and water content clearly indicated the vulnerability of SMPHL under processing, handling and storage conditions. The product would be difficult to dry as the conditions of outlet air (including: humidity and temperature) of the spray dryer would be closer or higher than the critical conditions. Since the Tg of SMPHL is so low, the molecular mobility of the solid will be high even at room temperature which might have led to deteriorative changes such as structural collapse, stickiness and caking.

Meanwhile, Langrish, et al. (2007) studied the comparison of maltodextrin and skim milk wall deposition rates in a pilot-scale spray dryer. Both maltodextrin and skim milk, with a solids content of $9 \%$ by mass, were sprayed in three repeated experiments. The same rates of cohesion and adhesion were observed for skim milk, while the maltodextrin (DE 18) showed lower overall deposition rates and particularly a lower rate of adhesion than for the subsequent cohesion of particles to each other after the initial spraying period. The lower deposition rates with maltodextrin than with skim milk are consistent with the higher glass transition temperature for dry maltodextrin. 
In another research by Fitzpatrick, et al. (2008), a novel easy-to-use force-displacement tester was developed from which an index of cake strength was obtained by measuring the peak force required to cause the powder cake to fail. The tester was used to investigate the consequence of temperature, relative humidity, exposure time and glass transition on the cake strength of SMP. Exposing SMP to high relative humidities of 76 and 100\% and temperatures in the range of $10-40{ }^{\circ} \mathrm{C}$ showed an increase in water sorption and cake strength over $24 \mathrm{~h}$ exposure time. A tough relationship between lactose glass transition and cake strength was confirmed. For the higher temperature condition of $40^{\circ} \mathrm{C}$, it was shown that the cake strength reached a maximum value and then decreased over time during a 1-week exposure time. This decrease may be due to lactose crystallisation. Crystallised lactose does not possess the sticky characteristic of amorphous lactose and inhibits the development of sinter bridge formation.

Not many researches have been carried out on freeze-dried dairy products. Among others, Elmonsef Omar, et al. (2007), had determined the glass transition temperatures for freeze dried powders of lactose and lactose/salt mixtures (9:1) at various water contents. They concluded that the Tg values decreased as water content increased as shown in Table 2.

They also concluded that crystallization in freeze-dried lactose and lactose/salt mixtures is mainly governed by the physical state of lactose. Stability of the amorphous products is concerned with material composition and storage conditions. Crystallization of amorphous lactose occurs above Tg but it becomes delayed by addition of salts. $\mathrm{Tg}$ of anhydrous lactose/salt mixtures seemed to be slightly higher than that of lactose, except for lactose $/ \mathrm{NaCl}$ and lactose $/ \mathrm{KCl}$.

In the DSC analysis, an endothermic relaxation peak was associated with the glass transition of pure lactose even in an immediate rescan of samples. Such relaxation was not observed in lactose/salt mixtures (as shown in Figure 8). Glass transition including enthalpy relaxation of pure lactose was broader than the glass transition of lactose/salt mixtures. The enthalpy relaxation suggested that lactose glass formed differently from a lactose/salt glass. This indicated that salts had similarities in affecting the relaxation and thermal behavior of amorphous lactose/salt mixtures (Elmonsef-Omar et al., 2007).

With regard to method in determining the glass transition temperature of skim milk powders, Thermal Mechanical Compression Test (TMCT) technique was found to be valid for the particle surface glass transition analysis of skim milk powder (Boonyai, et al., 2007). This technique gave a clear definition of the glass-rubber transition region and, therefore, allow accuracy of the Tg analysis. It was establish to be a very accurate and sensitive technique as compared to the standard DSC and TMA methods. It was recommended that this technique be explored further for application in the food powder industry.

Figure 9 demonstrates that changes in mechanical behaviour during the glass transition occurred at greater magnitude compared to the change in heat flow. In other words, mechanical techniques gave much clearer detection of the $\mathrm{Tg}$ than the thermal technique. This allows application of the mechanical techniques for analysis of the Tg of materials which do not exhibit clear changes in heat capacity (DCp). On comparing the two mechanical techniques, the new TMCT gave clearer and sharper changes in the probe displacement values. That was due to the characteristics and compression force capacities of the instrument. At optimal conditions for powder testing, TMCT was applied at higher compression and larger contact area and hence any small changes in mechanical properties of the material layer can be detected, whereas the maximum force that can be applied for thermomechanical analysis (TMA) testing was very low and changes in the probe displacement were subsequently smaller. If the same compression force were applied for both techniques, the mechanical behaviour changes may be comparable. The most important advantage of both mechanical techniques as compared to the thermal analysis using differential scanning calorimetry (DSC) was found in that the Tg region can be clearly identified for the $\mathrm{Tg}$ analysis due to the sharp changes in the probe displacement during the transition, with TMCT being the most sensitive (Boonyai et al., 2007).

Figure 12 shows the results of Tg values for SMP having different moisture contents as analysed using the TMCT, TMA and DSC (Boonyai et al., 2007).

\section{Rice kernels}

Drying has been used in rice processing and many researches related to its drying behavior and performances have been carried out. Rice kernel fissuring is a major rice industry problem. Fissured kernels may break during the milling process and thus reduce rice head yield (HRY). HRY is the current standard to assess commercial rice milling quality, and is defined as the weight percentage of rough rice that remains as head rice (kernels that are at least $3 / 4$ of the original kernel length) after complete milling. HRY reduction decreases the value of rice since broken kernels are typically worth half the value of head rice (Cnossen, et al., 2003). 
Theories on fissure formation, as a result of drying are based on the response of the rice kernels to tensile and compressive stresses due to moisture content (MC) gradients within the kernel. Cnossen, et al. (2003), confirmed that if rice sufficiently tempered and above the Tg to reduce MC gradients, a rubbery to glass state transition would not cause HRY reduction, if irreversible damage had not yet occurred. Insufficient MC gradient reduction before a state transition will produce fissures and consequent HRY reduction. This phenomenon is illustrated in Figure 11. The study has proved the hypothesis made by Cnossen \& Siebenmorgen (2000).

Yang, et al. (2003), who also studied the effect of drying on head rice yields, has further explained the relationship between the maximum moisture content gradient time and HRY variations. According to this study if the drying was carried out in a glassy region, no noticeable reduction in HRY could occur. If the rice was dried in the rubbery region, there was a maximum allowable percentage point of moisture removal, which proved to take place around the maximum moisture content gradient time, before HRY suffered a dramatic reduction if no immediate tempering followed drying.

Figures 12(a)-(e) show the drying behaviour of rice kernels in the pilot-scale cross-flow dryer. As can be seen, all the rice kernels at low moisture contents, as exemplified by the MC- curves, were dried in the glassy region at these five locations. At locations 1 and 2, most rice kernels entered the rubbery region during drying [Figures 12(a-b)]. From locations 3-5 [Figures 3(c-e), respectively], most rice kernels with moisture content above the mean moisture content ( $\mathrm{MC}$ curve) were dried in the rubbery region, while those below the $\mathrm{MC}$ curve were dried in the glassy region ( Yang, et al., 2003).

In another study, Yang, et al. (2003), examined the effect of glass transition temperature on the bulk thermal conductivity of rough rice. The thermal conductivity values ranged from 0.080 to $0.138 \mathrm{Wm}^{-1} \mathrm{~K}^{-1}$ measured using the line heat source method at initial temperatures of 3 to $69^{\circ} \mathrm{C}$ and moisture contents of $9.2-17.0 \%$ wet basis. The thermal conductivity values were computed using the maximum slope method. Thermal conductivity increased dramatically after the rice temperature increased above the glass transition temperature $\mathrm{Tg}$. The thermal conductivity was relatively constant from around $25^{\circ} \mathrm{C}$ to the $\mathrm{Tg}$, and decreased with decreasing temperature below $25^{\circ} \mathrm{C}$. It was found that the thermal conductivity of rough rice increased with increasing moisture content. A multiple regression equation relating thermal conductivity to temperature and moisture content was developed through stepwise regression analysis. It was found that the thermal conductivity changed little below and increased considerably above the glass transition temperature.

Subsequently, they also developed a mathematical models describing heat and moisture movements inside a rice kernel during drying using the finite element method, and the intrakernel moisture content gradients during drying were predicted and analysed. The relationship of intra-kernel moisture content gradients and glass transition temperatures to HRY variations during drying was examined. It was found that when a drying temperature was below the glass transition temperature of rice kernels and the drying took place in the glassy region, HRY reduced little with an increased drying duration. When rice was dried in the rubbery region and no tempering was performed immediately after drying, there existed a limit for the percentage points of moisture content removal per drying pass beyond which HRY would incur a dramatic decrease. This turning point in head rice yield trend was found to coincide with the time when the maximum moisture content gradient occurred.

\section{Starch and sugar products}

Yeting Liu, et al. (2007), reported that amorphous starch syrup solid (GSS) with higher glass transition temperature played the role of anti-plasticizer in the amorphous mixture system containing sucrose and GSS. However, addition of GSS up to $50 \% \mathrm{w} / \mathrm{w}$ in his study did not increase the mixture's glass transition temperature significantly compared to the sucrose's glass transition temperature. This indicated that the ideal mixing was not achieved. Addition of GSS into sucrose increased the mean relaxation times dramatically at all aging temperatures through decreasing the molecular mobility significantly. Normally, the more the GSS added, the longer the mean relaxation time of the mixture, at the aging temperatures that have the same distance below their corresponding glass transition temperatures. Through the comparison of apparent activation energy of the mean relaxation time for all samples, addition of GSS into sucrose up to $50 \%$ did not change the susceptibility significantly. Addition of GSS into sucrose increased the relaxation time distribution spectrum through increasing the complexity of molecular weight distribution in the mixture. The results of the experiment are as shown in Table 3.

Stefan Kasapis, et al. (2008), studied the effect of pressure on the vitrification of biomacromolecules (gelling polysaccharide/ co-solute). Biopolymers used are gelling polysaccharides namely agarose, K-carrageenan and deacylated gellan. They concluded that pressure-induced vitrification patterns appear to be largely irreversible due to the destabilization of the remaining aggregated assemblies of the high co-solute polysaccharide networks. So 
disruption and the slow kinetics of recovery of the brittle polysaccharide agglomerates guide to lower values in the micro and macro-examination of the glass transition temperature.

Figure 13 shows the appearance of an Arrhenius-related linear superposition delimits a discontinuity in the development of shift factors at the end of the WLF curvature upon cooling. This vary in operational kinetics can be consider to be a measure of the basic glass transition temperature at which free volume considerations become secondary to an energetic barrier of molecular rearrangements from one state to another. This exercise gave a clear confirmation that the temperature-course of vitrification phenomena is altered considerably within the experimentally accessible range of pressure $(0.1$ to $700 \mathrm{MPa})$ thus creating a differential of about five to six degrees centigrade for the mechanical glass transition temperature (Stefan Kasapis et al., 2008).

Caking or sticking of amorphous substances, which is a sort of undesired agglomeration, is frequently observed. Any desired or undesired agglomeration of amorphous substances is dependent on the mechanical properties of the entire particle or the particle surface. Changes in the mechanical properties of the material are linked to changes in moisture and temperature and can be predicted by applying the glass transition concept. By this idea it is possible to guess the viscosity and the Young's modulus for a given amorphous substance while knowing their glass transition temperature in dependence on the water content. Knowing the viscosity and the Young's modulus and applying equations derived from the sintering technology or the theory of viscoelasticity it is possible to define suitable conditions for most of the agglomeration processes (Stefan Palzer, 2005).

Glass formation (vitrification) is a well-known strategy to solidify and protect sensitive materials in biological systems. Also, protection by glasses is applied both in pharmaceutical and food industries to maintain the quality of a solidified product. A glass can be considered as a solid liquid with an extremely high viscosity. Low temperature and low water content increase the viscosity of a liquid finally resulting in a brittle glass. Due to the high viscosity, stability of the incorporated biological compound is maintained for a long period of time (Stefan Palzer, 2005).

Figure 16 shows the glass transition temperature curve for glucose syrup (dextrose syrup with a dextrose equivalent DE of 21). Spraying water into a fluidised bed of particles always results in a moisture distribution among the single particles. Some particles or at least some parts of the particle surface are extremely moist and some regions remain dry. However, for agglomeration only a certain quantity of particles or a certain part of the particle surface has to reach the moisture/ temperature conditions, which provide sufficient adhesion forces. These particles will stick other particles which are still dry together. Assuming a monodisperse distribution of equally shaped particles and a cubic packaging, at least one out of seven particles has to become sticky enough to fix six dry particles together. The assumption of such an agglomeration mechanism is supported by the electron microscopy picture of the agglomerated powder included in Figure 16. Obviously, the resulting average water activity and the corresponding surface moisture of such an agglomerated powder are lower than the value calculated for a homogenous moisture distribution resulting in a collapse of the powder bed. The water activities measured for different agglomeration trials just after the spraying step are included in Figure 16 (triangular symbols). After agglomeration the moist powder has to be dried to void the risk of caking during storage. The final moisture content should thus correspond to a glass transition temperature, which is $5-10{ }^{\circ} \mathrm{C}$ higher than the storage temperature (Stefan Palzer, 2005).

Jeong-Ah Seo, et al. (2006), concluded that the glass transition temperatures of sugar mixtures are strongly affected by the size and the shape of sugar molecules. Figure 15 shows the glass transition temperatures of the monosaccharide-trisaccharide (glucose-maltotriose) mixtures. The solid line is the fitted result using the modified Gordon-Taylor equation and the dashed line is the fitted result using the conventional Gordon-Taylor equation. As expected, the glass transition temperatures showed a clear deviation from the Gordon-Taylor equation and the amount of deviation is larger than that in the monosaccharide-disaccharide mixtures. In the case of the monosaccharide-trisaccharide mixture, the dashed lines also crossed with the solid lines at the point where the weight fraction $\mathrm{W}=0.26$, and this crossing point also corresponds to the case when $\mathrm{M}=0.5$. This is a similar behavior with sorbitol-sucrose mixtures.

Adhikari, et al. (2009), reported the effect of addition of proteins on the production of amorphous sucrose powder through spray drying. $0.5-1 \%$ sodium caseinate and Whey Protein Isolate on a dry solid basis were added to sucrose and spray dried with inlet and outlet temperatures of $160{ }^{\circ} \mathrm{C}$ and $70{ }^{\circ} \mathrm{C}$, respectively. This amount of protein addition was sufficient to convert the crystalline sucrose (first converting it into aqueous solution) into amorphous form. The recovery of powder was also increased from $0 \%$ of pure sucrose to greater than $80 \%$ in the presence of these proteins. This is attributed to two reasons. Firstly, protein preferentially migrates to the droplet-air interface driven by its surface activity. Secondly, it forms a thin protein-rich film soon after coming in 
contact with drying air. The film converts into glassy state and acts to beat both the particle-to-particle and particle-to-wall stickiness by raising the glass transition temperature of the surface layer.

According to F.P. Collares, et al. (2004), the detachment of films of food pastes from a solid surface during a drying process is determined by the glass transition conditions of the paste. Detachment occurs when the film moisture achieves values corresponding to the glass transition curve. Thus the higher the temperature of the air inside the chamber, the lower the paste film moisture content should be, in order to allow for the separation. Food formulations with glass transition conditions unattainable during the drying process, such as sugar cane molasses, will not separate. Glass transition curves (state diagrams) should be obtained prior to establishing the relationship between composition and the physical state of the food paste, providing data for the suitable reformulation or choice of operational drying conditions that would encourage the detachment of the dried paste, enhancing the drying yield.

There is a study on freeze dried fruit paste. Jasim Ahmed, et al. (2005), investigated the effect of water activity on glass transitions of date pastes. Freeze dried date paste sample adsorbed moisture rapidly compared to the control sample (without freeze drying) due to the presence of void spaces created during the freeze drying process. Glass transition temperatures of saturated salt equilibrated samples were determined and it was found that $\mathrm{Tg}$ ranged between -1.98 and $-81.44{ }^{\circ} \mathrm{C}$. Differences in Tg observed between control and freeze dried date paste samples supported the sorption data.

Moisture sorption isotherms of both date paste samples at $20{ }^{\circ} \mathrm{C}$ are shown in Figure 16. It shows that at lower $\mathrm{a}_{\mathrm{w}}$ values, little difference in moisture adsorption patterns of paste was observed. However, it became significant with increase in water activity. This is due to water sorption onto primary sites of hydrophilic compounds present in the dates (Jasim Ahmed et al., 2005).

\section{Freeze-dried strawberries}

In drying process of strawberries, the relationship between glass transition temperature and rehydration was interpreted from porosity and collapse during drying. Shrinkage and collapse occur when the solid matrix of the strawberries can no longer support its own weight, leading to drastic structural changes when held at temperature above its $\mathrm{Tg}$ at a particular moisture content (Ratti, 2001).

Figure 19 reveals the progression of the product temperature of strawberries during air and freeze drying as compared to its glass transition temperature at comparable moisture contents (air dried at $50^{\circ} \mathrm{C}$ and freeze dried at $20^{\circ} \mathrm{C}$ ). In the case of air-drying, the product temperature was above Tg during the whole process, which demonstrate that collapse and poor quality should be expected when air drying. On the other hand, product freeze drying temperature was below Tg only at the end of the process. These results supported previous studies that collapse is a time-temperature phenomenon and $\mathrm{Tg}$ of dry solids would be a crucial parameter for freeze-drying process (Ratti, 2001).

\section{Freeze-dried surimi products}

The glass transition properties of frozen and freeze-dried surimi products were investigated by Chisato Ohkuma, et al. (2008). It was demonstrated that the frozen surimi samples showed two freeze-concentrated glass transitions at -42 to $-65{ }^{\circ} \mathrm{C}$ and at -21 to $-41{ }^{\circ} \mathrm{C}$, depending on the types and content of sugar. $\operatorname{The} \operatorname{Tg}(\mathrm{s})$ of the surimi-trehalose mixture was slightly higher than that of trehalose; this is because surimi plays the role of anti-plasticizer to trehalose. The surimi-trehalose mixture has greater resistance to a decrease in $\mathrm{Tg}$ induced by the plasticizing effect of water and a greater amount of unfrozen water in the maximally freeze-concentrated glassy state than trehalose does. These observations suggest that the glassy properties of trehalose were affected by intermolecular interaction between surimi and trehalose (Chisato Ohkuma et al., 2008).

Typical DSC thermograms for carp surimi-trehalose mixtures of varying trehalose content $(0-75.4 \%$ in dry matter) are shown in Figure 20. The mixtures containing $0 \%$ and $16.9 \%$ trehalose showed no apparent thermal event except ice-melting. The mixtures containing 34.2\%, 54.2\%, and $75.4 \%$ trehalose, on the other hand, showed two characteristic thermal events: a small endothermic shift at a low temperature and an endothermic shoulder immediately before ice-melting. These endothermic events were judged to be freeze-concentrated glass transitions. The magnitude of the endothermic events reflecting T'g1 and T'g2 increased with increasing trehalose content. Additionally, the T'g1 and T'g2 increased and decreased, respectively. The mixtures containing other types of sugar showed similar results to those in Figure 20 (Chisato Ohkuma et al., 2008).

\section{Conclusion}

From all the publications, it can be concluded that glass transition temperature is a significant element which can be used in predicting the behavior of food products during processing where changes in temperature occur. The 
studies revealed that the major component of the specified food (which consist of mixture of ingredients), for example lactose in skim milk powder and sucrose in sugar mixtures, will influence the glass transition temperature of the food. Tg is an important aspect in determining the optimum processing conditions of dried products which result in required product quality, thus, it is used in designing equipment to meet the purpose. In general, Tg contributes to the physical properties of food such as stickiness, caking and agglomeration. The effect of moisture content on Tg is covered by almost all studies concerning Tg of food. Meanwhile, the effect of pressure on Tg is not well covered. In term of test method in determining the Tg of food, it seems that not any test method best for certain type of food, more study on the recommended test method should be carried out.

\section{References}

Adhikari, B., T. Howes, B.R. Bhandari, T.A.G. Langrish. (2009). Effect of addition of proteins on the production of amorphous sucrose powder through spray drying. Journal of Food Engineering 94 (2009) 144-153.

Boonyai, P., T. Howes, B. Bhandari. (2007). Instrumentation and testing of a thermal mechanical compression test for glass-rubber transition analysis of food powders. Journal of Food Engineering 78 (2007) 1333-1342.

Chisato Ohkuma, Kiyoshi Kawai, Chotika Viriyarattanasak, Thanachan Mahawanich, Sumate Tantratian, Rikuo Takai, Toru Suzuki. (2008). Glass transition properties of frozen and freeze-dried surimi products: Effects of sugar and moisture on the glass transition temperature. Food Hydrocolloids 22 (2008) 255-262.

Cnossen, A.G. M.J. Jimėnez, T.J. Siebenmorgen. (2003). Rice fissuring response to high drying and tempering temperatures. Journal of Food Engineering 59 (2003) 61-69.

Collares, F.P. , J.R.D. Finzer, T.G. Kieckbusch. (2004). Glass transition control of the detachment of food pastes dried over glass plates. Journal of Food Engineering 61 (2004) 261-267.

Elmonsef -Omar, A.M., Yrjö H. Roos. (2007). Glass transition and crystallization behaviour of freeze-dried lactose-salt mixtures. LWT 40 (2007) 536-543.

Fitzpatrick, J.J., E. O’Callaghan, J. O’Flynn. (2008). Application of a novel cake strength tester for investigating caking of skim milk powder. Food and bioproductprocessing 86 (2008) 198 - 203.

Fitzpatrick, J.J., M. Hodnett, M. Twomey, P.S.M. Cerqueira, J. O'Flynn, Y.H. Roos. (2007). Glass transition and the flowability and caking of powders containing amorphous lactose. Powder Technology 178 (2007) 119-128.

Jasim Ahmed, H.S. Ramaswamy, A.R. Khan. (2005). Effect of water activity on glass transitions of date pastes. Journal of Food Engineering 66 (2005) 253-258.

Jeong-Ah Seo, S. J. Kim, Hyun-Joung Kwon, Y. S. Yang, Hyung Kook Kim and Yoon-Hwae Hwang. (2006). The glass transition temperatures of sugar mixtures. Carbohydrate Research 341 (2006) 2516-2520.

Langrish, T.A.G. W.C. Chan, K. Kota. (2007). Comparison of maltodextrin and skim milk wall deposition rates in a pilot-scale spray dryer. Powder Technology 179 (2007) 84-89.

Langrish. T.A.G. (2008). Assessing the rate of solid-phase crystallization for lactose: The effect of the difference between material and glass-transition temperatures. Food Research International 41 (2008) 630-636.

Ratti. C. (2001). Hot air and freeze-drying of high-value foods: a review. Journal of Food Engineering 49 (2001): 311-319.

Shrestha, A.k., Tony Howes, Benu P. Adhikari, Bhesh R. Bhandari. (2007). Water sorption and glass transition properties of spray dried lactose hydrolysed skim milk powder. LWT 40 (2007) 1593-1600.

Shrestha, A.k., Tony Howes, Benu P. Adhikari, Barry J. Wood, Bhesh R. Bhandari. (2007). Effect of protein concentration on the surface composition, water sorption and glass transition temperature of spray-dried skim milk powders. Food Chemistry 104 (2007) 1436-1444.

Stefan Kasapis. (2006). Definition and applications of the network glass transition temperature. Food Hydrocolloids 20 (2006) 218-228.

Stefan Kasapis, Shyam S. Sablani. (2008). The effect of pressure on the structural properties of biopolymer/co-solute. Part II: The example of gelling polysaccharides. Carbohydrate Polymers 72 (2008) 537-544

Stefan Palzer. (2005). The effect of glass transition on the desired and undesired agglomeration of amorphous food powders. Chemical Engineering Science 60 (2005) 3959 - 3968. 
Ted Labuza, Karl Roe, Camy Payne, Fern Panda, Theodore J. Labuza, Peter S. Labuza and Laura Krusch. (2004). Storage stability of dry food systems: Influence of state changes during drying and storage. Proceedings of the $14^{\text {th }}$ International Drying Symposium (IDS 2004). Drying 2004. Vol. A. pp. 48-68.

Yang W., C.-C. Jia; T.J. Siebenmorgen; Z. Pan; A.G. Cnossen. (2003). Relationship of Kernel Moisture Content Gradients and Glass Transition Temperatures to Head Rice Yield. Biosystems Engineering (2003) 85 (4), 467-476.

Yang W., C.-C. Jia; T.A. Howell. (2003). Relationship of Moisture Content Gradients and Glass Transition Temperatures to Head Rice Yield during Cross-Flow Drying. Biosystems Engineering (2003) 86 (2), 199-206.

Yang W., T. J. Siebenmorgen; T. P. H. Thielen; A. G. Cnossen. (2003). Effect of Glass Transition on Thermal Conductivity of Rough Rice. Biosystems Engineering (2003) 84 (2), 193-200.

Yeting Liu, Bhesh Bhandari, Weibiao Zhou. (2007). Study of glass transition and enthalpy relaxation of mixtures of amorphous sucrose and amorphous tapioca starch syrup solid by differential scanning calorimetry (DSC). Journal of Food Engineering 81 (2007) 599-610.

Table 1. Effect of temperature, relative humidity $(\mathrm{RH})$ and exposure time on the water content, cake strength and $[\mathrm{T}-\mathrm{Tg}]^{+}$of skim milk powder (where $\mathrm{T}$ is the powder exposure temperature and $\mathrm{Tg}$ is the glass tranistion temperature of lactose at the powder water content. If $\mathrm{T}-\mathrm{Tg}<0$, then $[\mathrm{T}-\mathrm{Tg}]^{+}=0$ ). (Ref: J.J. Fitzpatrick et al., 2007)

\begin{tabular}{|c|c|c|c|c|c|c|}
\hline Time (h) & $\begin{array}{l}76 \% \mathrm{RH} \\
10{ }^{\circ} \mathrm{C}\end{array}$ & $\begin{array}{l}76 \% \mathrm{RH} \\
25{ }^{\circ} \mathrm{C}\end{array}$ & $\begin{array}{l}76 \% \mathrm{RH} \\
40^{\circ} \mathrm{C}\end{array}$ & $\begin{array}{l}100 \% \mathrm{RH} \\
10^{\circ} \mathrm{C}\end{array}$ & $\begin{array}{l}100 \% \mathrm{RH} \\
25^{\circ} \mathrm{C}\end{array}$ & $\begin{array}{l}100 \% \mathrm{RH} \\
40{ }^{\circ} \mathrm{C}\end{array}$ \\
\hline \multicolumn{7}{|c|}{ Water content $(\% \mathrm{w} / \mathrm{w})$} \\
\hline 0 & 5.2 & 5.2 & 5.2 & 5.2 & 5.2 & 5.2 \\
\hline 2 & 7 & 6.4 & 7.8 & 7.9 & 7.2 & 9.6 \\
\hline 4 & 7.3 & 7.5 & 10.5 & 8 & 9 & 13.9 \\
\hline 6 & 8 & 8.8 & 11.2 & 9.4 & 11 & 15 \\
\hline 12 & 8.7 & 12.2 & 13 & 14 & 14 & 18 \\
\hline 24 & 12.4 & 14.4 & 13.8 & 18.4 & 17.9 & 22 \\
\hline \multicolumn{7}{|c|}{ Cake strength $(\mathrm{N})$} \\
\hline 0 & 0 & 0 & 0 & 0 & 0 & 0 \\
\hline 2 & 0.04 & 0.04 & 0.03 & 0.15 & 0.1 & 1.7 \\
\hline 4 & 0.06 & 0.03 & 1.06 & 0.1 & 0.23 & 4 \\
\hline 6 & 0.32 & 0.4 & 1.9 & 0.7 & 2.7 & 4.9 \\
\hline 12 & 0.25 & 1.8 & 2.2 & 1 & 3.1 & 5.4 \\
\hline 24 & 1.1 & 1.9 & 3.5 & 1.8. & 3.1 & 7.8 \\
\hline \multicolumn{7}{|c|}{$\left[T-T_{\mathrm{g}}\right]^{+}\left({ }^{\circ} \mathrm{C}\right)$} \\
\hline 0 & 0 & 0 & 0 & 0 & 0 & 0 \\
\hline 2 & 0 & 0 & 0 & 0 & 0 & 0 \\
\hline 4 & 0 & 3 & 20 & 0 & 14 & 52 \\
\hline 6 & 0 & 12 & 38 & 2 & 25 & 56 \\
\hline 12 & 0 & 30 & 41 & 22 & 37 & 69 \\
\hline 24 & 15 & 38 & 51 & 40 & 53 & 88 \\
\hline
\end{tabular}


Table 2. Glass transition temperatures $(\mathrm{Tg})$, (mean values $\pm \mathrm{SD}$ ) for freeze-dried lactose and lactose/salt mixtures (in ratio of 9:1) stored for $96 \mathrm{~h}$ at various relative vapour pressures (RVP) of water.

(Ref: A.M. Elmonsef Omar et al, 2007)

\begin{tabular}{|c|c|c|c|c|c|c|c|c|c|c|}
\hline \multicolumn{11}{|c|}{ Glass transition temperature $\left({ }^{\circ} \mathrm{C}\right)$} \\
\hline \multirow[t]{2}{*}{ Materials } & \multicolumn{2}{|l|}{$0.0 \%$ RVP } & \multicolumn{2}{|l|}{$11.6 \%$ RVP } & \multicolumn{2}{|l|}{$23.2 \% \mathrm{RVP}$} & \multicolumn{2}{|l|}{$33.5 \%$ RVP } & \multicolumn{2}{|c|}{$44.0 \% \mathrm{RVP}$} \\
\hline & $T_{\mathrm{g} 1}$ & $T_{\mathrm{g} 2}$ & $T_{\mathrm{cr}}$ & $T_{\mathrm{cr}}^{\mathrm{p}}$ & $T_{\mathrm{g} 1}$ & $T_{\mathrm{g} 2}$ & $T_{\mathrm{g} 1}$ & $T_{\mathrm{g} 2}$ & $T_{\mathrm{g} 1}$ & $T_{\mathrm{g} 2}$ \\
\hline Lactose & $105.5 \pm 1.1 \mathrm{a}$ & $120.5 \pm 0.5 \mathrm{a}$ & $62.2 \pm 0.7 \mathrm{a}$ & $76.4 \pm 0.4 \mathrm{a}$ & $45.9 \pm 0.4 a$ & $59.4 \pm 0.2 \mathrm{a}$ & $30.5 \pm 0.2 \mathrm{a}$ & $43.2 \pm 0.1 \mathrm{a}$ & $11.3 \pm 0.4 \mathrm{a}$ & $25.4 \pm 0.4 \mathrm{a}$ \\
\hline Lactose $/ \mathrm{CaCl}_{2}$ & $121.6 \pm 0.1 \mathrm{~b}$ & $132.5 \pm 0.3 b$ & $64.6 \pm .02 b$ & $82.4 \pm 0.1 b$ & $40.5 \pm 0.6 b$ & $56.5 \pm 0.2 b$ & $26.9 \pm 0.5 b$ & $44.9 \pm 0.4 b$ & $13.4 \pm 0.8 b$ & $27.8 \pm 0.3 b$ \\
\hline Lactose $/ \mathrm{NaCl}$ & $99.9 \pm 0.8 \mathrm{c}$ & $116.7 \pm 0.3 \mathrm{c}$ & $58.8 \pm 0.5 \mathrm{c}$ & $74.5 \pm 1 \mathrm{c}$ & $39.6 \pm 0.3 \mathrm{c}$ & $55.1 \pm 0.3 \mathrm{c}$ & $24.6 \pm 0.2 \mathrm{c}$ & $39.3 \pm 0.4 \mathrm{c}$ & $5.9 \pm 0.2 \mathrm{c}$ & $20.3 \pm 0.2 \mathrm{c}$ \\
\hline Lactose $/ \mathrm{MgCl}_{2}$ & $113.7 \pm 0.5 \mathrm{~d}$ & $129 \pm 0.4 \mathrm{~d}$ & $62.3 \pm 0.3 \mathrm{a}$ & $78.2 \pm 0.4 \mathrm{~d}$ & $39.5 \pm 0.2 \mathrm{c}$ & $54.1 \pm 0.6 \mathrm{~d}$ & $26.6 \pm 0.3 b$ & $40.7 \pm 0.1 \mathrm{~d}$ & $6.1 \pm 0.4 \mathrm{c}$ & $17.9 \pm 0.6 \mathrm{~d}$ \\
\hline Lactose $/ \mathrm{KCl}$ & $98.8 \pm 0.4 \mathrm{c}$ & $114.3 \pm 0.2 \mathrm{e}$ & $58.9 \pm 1.4 \mathrm{c}$ & $70.4 \pm 0.4 \mathrm{e}$ & $37.9 \pm 0.6 \mathrm{~d}$ & $54.7 \pm 0.2 \mathrm{e}$ & $24.1 \pm 0.1 \mathrm{~d}$ & $38.4 \pm 0.1 \mathrm{e}$ & $6.6 \pm 0.6 \mathrm{c}$ & $20.8 \pm 0.7 \mathrm{c}$ \\
\hline
\end{tabular}

$T_{\mathrm{g} 1}$, onset of glass transition; $T_{\mathrm{g} 2}$, endset of glass transition.

Water activity at $23^{\circ} \mathrm{C} ; a_{\mathrm{w}}=0.01 \times \mathrm{RVP}$ at equilibrium.

Mean values \pm standard deviation followed by different letters within the same columns differ significantly $(P \leqslant 0.05)$.

Table 3. Experimental glass transition temperatures and specific heat change values through glass transition zone of sucrose, S75G25, S50G50, S25G75 and GSS (Ref: Yeting Liu et al., 2007).

\begin{tabular}{lllll}
\hline & $\begin{array}{l}T_{\mathrm{g}} \text { onset } \\
\left({ }^{\circ} \mathrm{C}\right)\end{array}$ & $\begin{array}{l}T_{\mathrm{g}} \text { midpoint } \\
\left({ }^{\circ} \mathrm{C}\right)\end{array}$ & $\begin{array}{l}T_{\mathrm{g}} \text { endpoint } \\
\left({ }^{\circ} \mathrm{C}\right)\end{array}$ & $\begin{array}{l}\Delta C_{\mathrm{p}} \\
\left(\mathrm{J} \mathrm{g}^{-1} \mathrm{~K}^{-1}\right)\end{array}$ \\
\hline Sucrose & $67.19 \pm 0.49$ & $69.70 \pm 0.34$ & $72.73 \pm 0.17$ & $0.648 \pm 0.010$ \\
S75G25 & $52.98 \pm 1.75$ & $57.96 \pm 1.64$ & $63.60 \pm 1.27$ & $0.654 \pm 0.011$ \\
S50G50 & $61.94 \pm 1.08$ & $68.28 \pm 0.89$ & $74.30 \pm 1.00$ & $0.600 \pm 0.014$ \\
S25G75 & $71.52 \pm 1.42$ & $78.13 \pm 1.14$ & $84.27 \pm 0.94$ & $0.528 \pm 0.022$ \\
GSS & $73.36 \pm 2.24$ & $81.28 \pm 2.16$ & $88.18 \pm 2.03$ & $0.505 \pm 0.140$ \\
\hline
\end{tabular}

"The values reported are mean value \pm standard derivation.

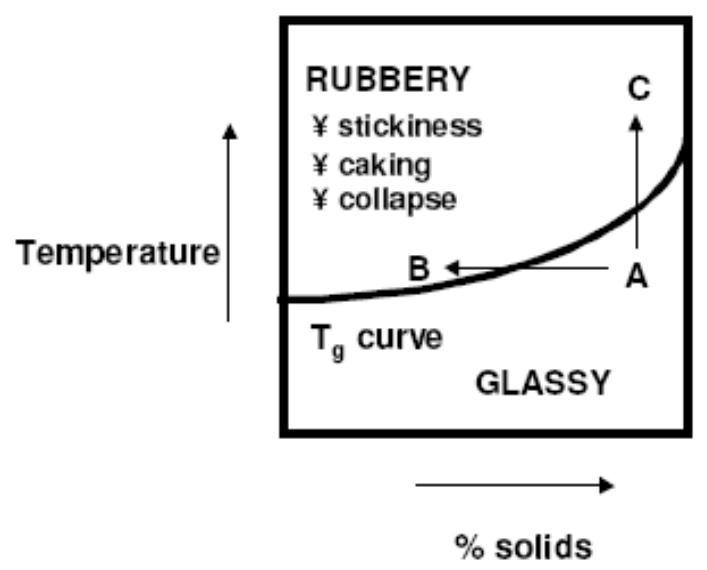

Figure 1. Representative glass rubber transition diagram for an amorphous material.

(Ref: Ted Labuza et al., 2004) 


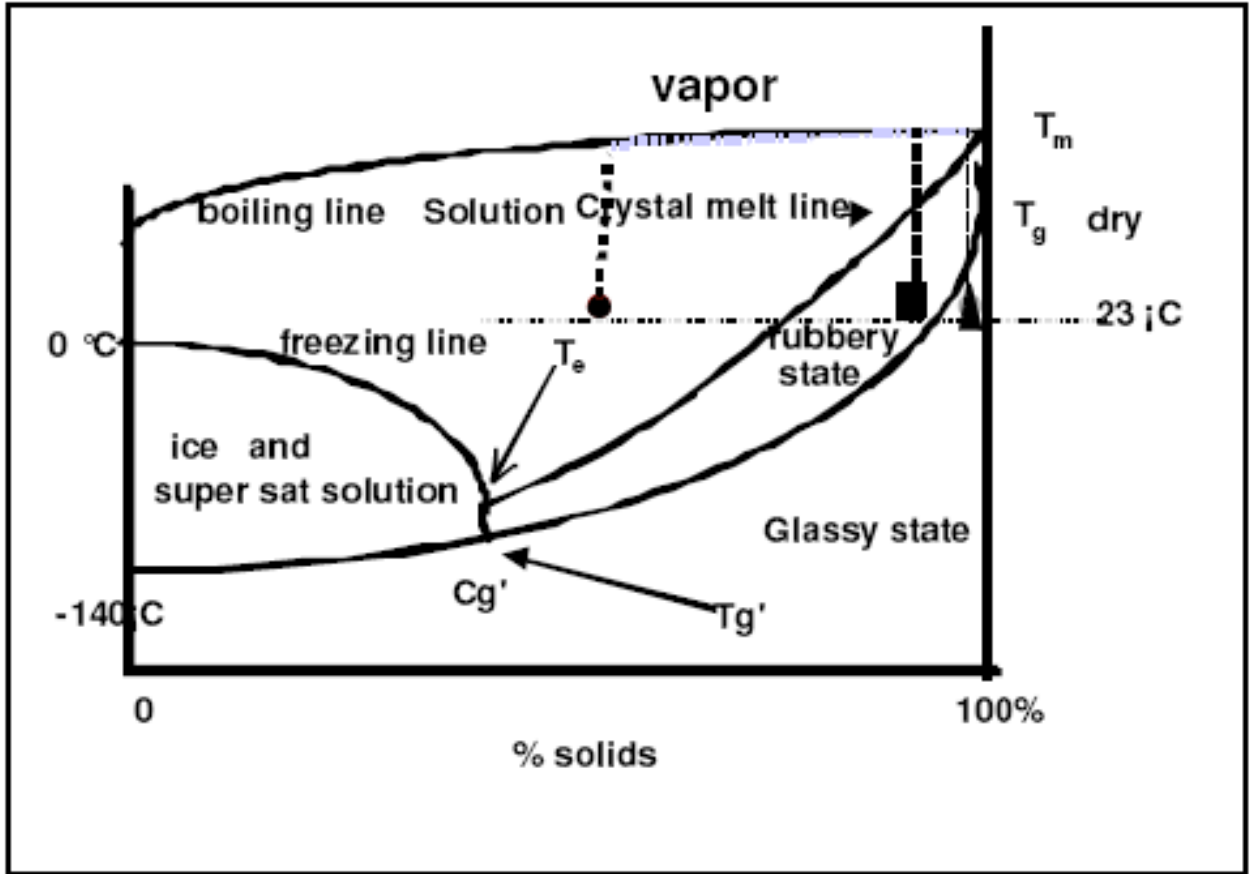

Figure 2. Hypothetical State diagram showing equilibrium and amorphous regions State $1 \bullet$ Initial non equilibrium sugar mix or cereal dough

State 2 - Final rubbery state eg for soft cookie or caramel

State $3 \Delta$ Final glassy state for hard ball candy, cotton candy or crisp cookie. (Ref: Ted Labuza et al., 2004)

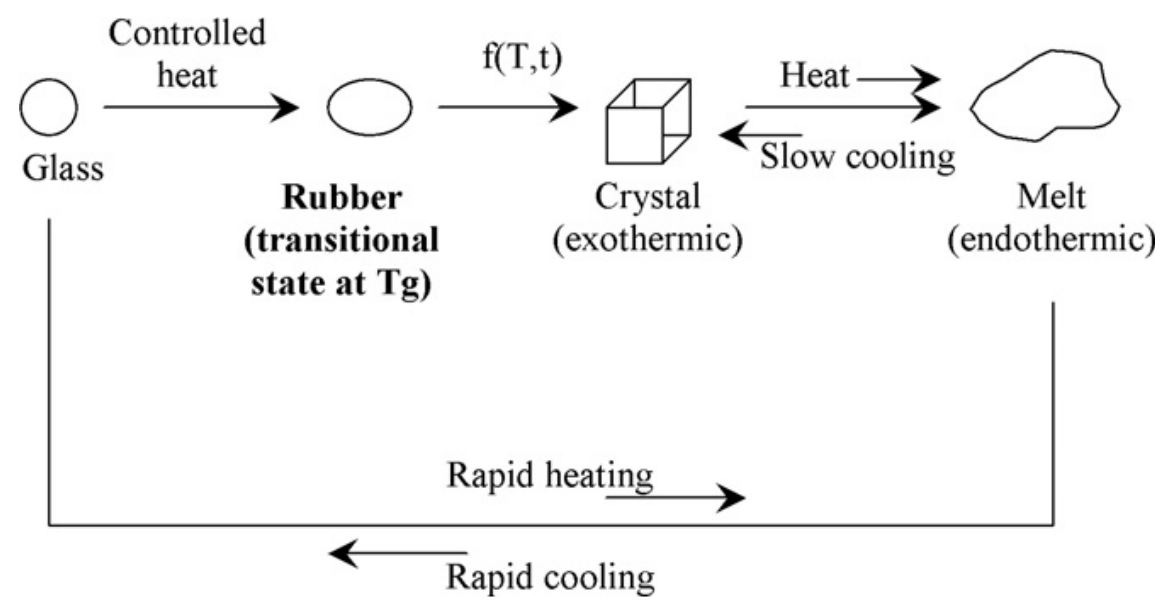

Figure 3. Change of physical state of an amorphous glass through rubbery (transitional) to crystalline state, $\mathrm{T}$ - temperature, $\mathrm{t}$ - time. (Ref: Langrish, 2008) 


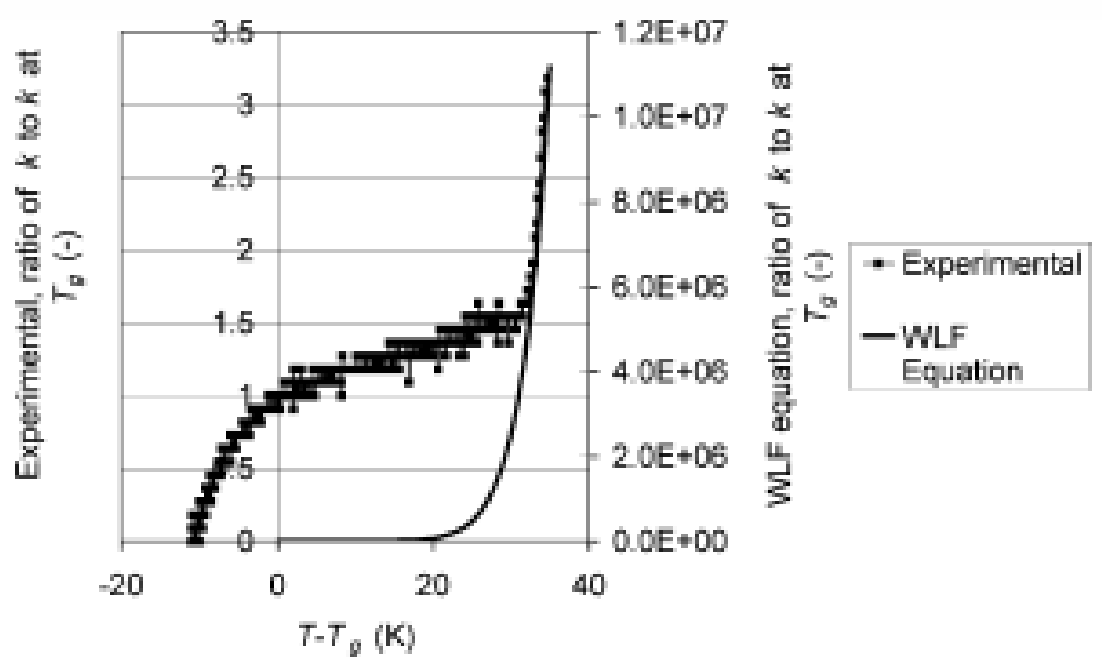

Figure 4. The experimental ratio of the rate of change in the degree of crystallinity $(\mathrm{k})$ to the rate of change at the glass-transition temperature $(\mathrm{k}$ at $\mathrm{Tg})$ for spray-dried lactose, together with the same ratio obtained from the WLF Eq. as functions of the differences between the material and the glass-transition temperatures $(\mathrm{T}-\mathrm{Tg})$.

(Ref: Langrish, 2008)

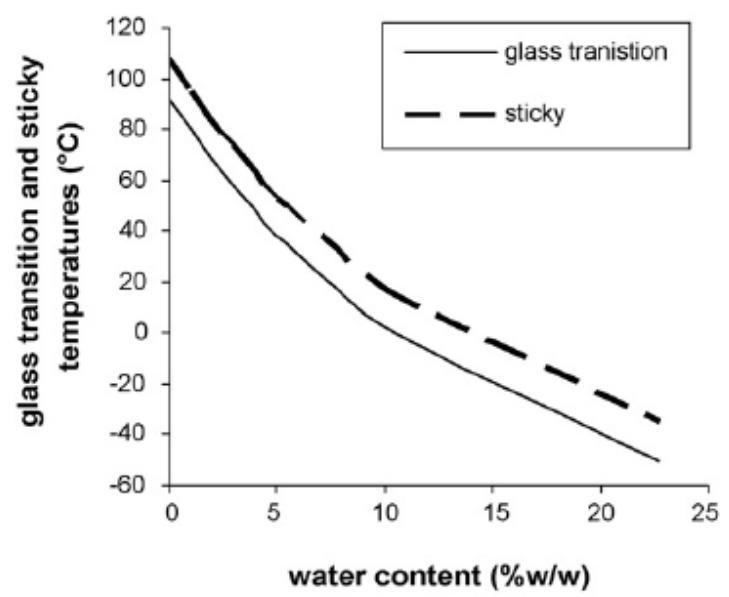

Figure 5. Glass transition (onset) and sticky temperature of lactose in skim milk powder.

(Ref: J.J. Fitzpatrick et al., 2007) 


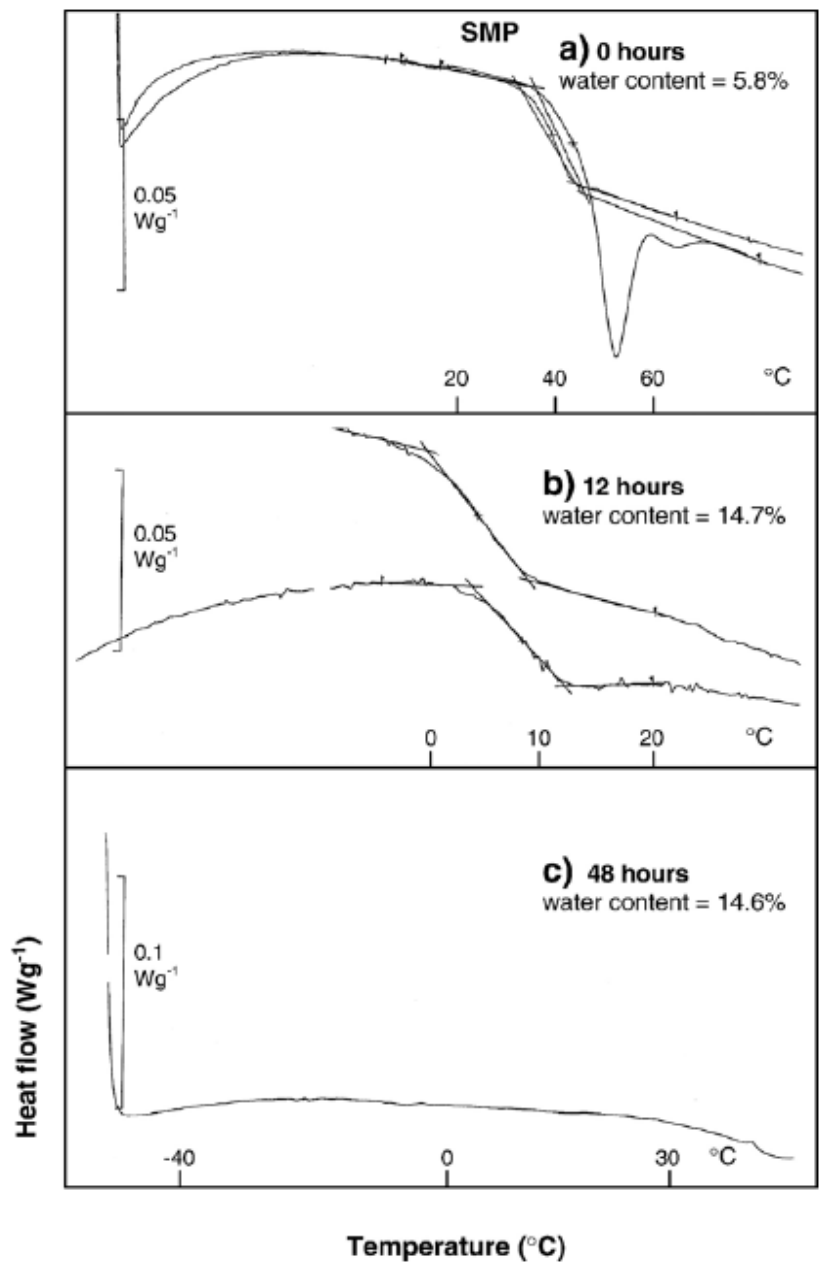

Figure 6. DSC thermograms of skim milk powder (SMP) exposed to $76 \% \mathrm{RH}$ at $20^{\circ} \mathrm{C}$ for a) $0 \mathrm{~h}$; b) $12 \mathrm{~h}$; c) $48 \mathrm{~h}$.

(Ref: J.J. Fitzpatrick et al., 2007)

A

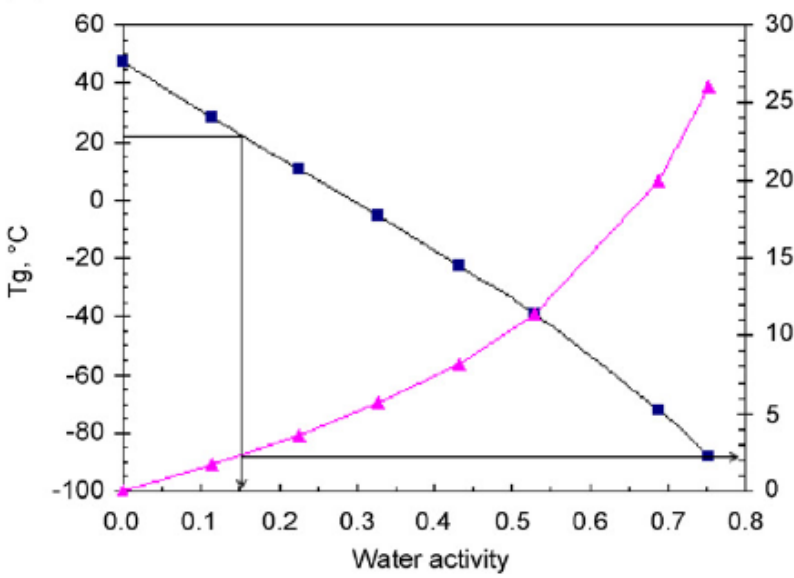

B

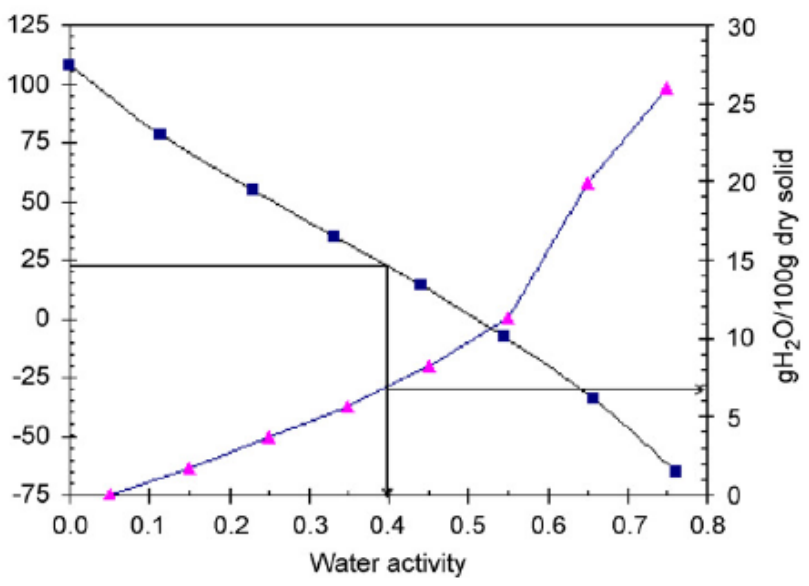

Figure 7. Relationship between the water activities at $23{ }^{\circ} \mathrm{C}$, water content $(\boldsymbol{\Delta})$ and glass transition temperature, $\operatorname{Tg}(\boldsymbol{\Xi})$ of SMPHL (A) pure lactose (B). The water content and Tg values of SMPHL and lactose were predicted by BET models and Gordon-Taylor equation, respectively. The critical Tg and water activity for both the powders are shown by the arrows. (Ref: Ashok K. Shrestha et al., 2007) 


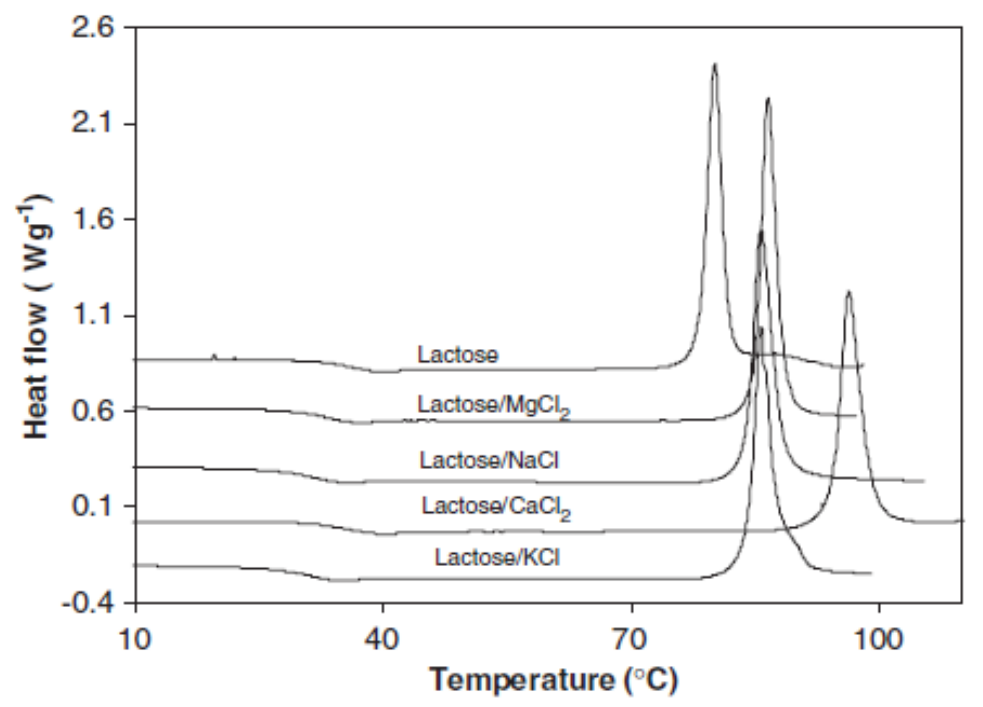

Figure 8. Dynamic DSC curves for freeze-dried lactose and lactose/salt mixtures, stored $96 \mathrm{~h}$ at relative vapour pressure (RVP) of $33.5 \%$ at room temperature. The thermograms show glass transition, crystallizationtemperature, and the peak of crystallization. Scanning rate was $5{ }^{\circ} \mathrm{C} / \mathrm{min}$. (Ref: A.M. Elmonsef Omar et al, 2007)

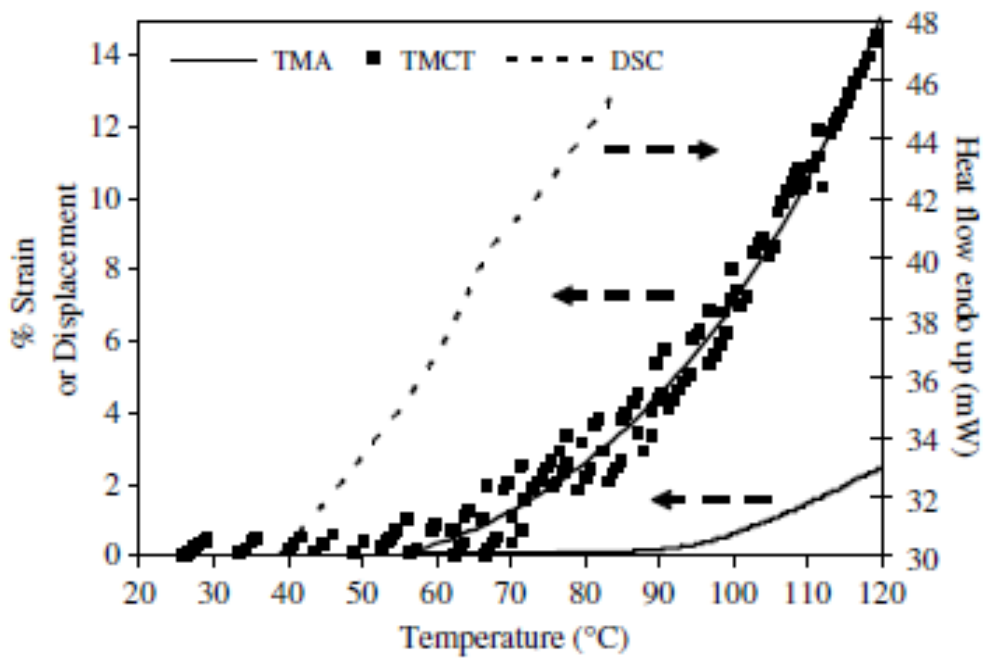

Figure 9. Typical heat flow and mechanical behaviours of skim milk powder with $2.01 \%$ (dry basis) moisture content during glass transition. (Ref: P. Boonyai et al., 2007) 


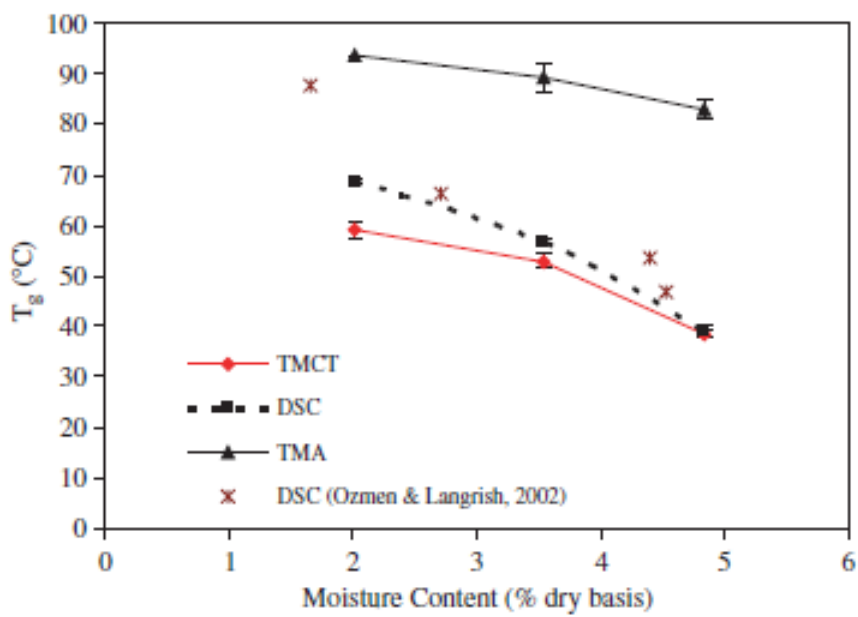

Figure 10. Comparison of Tg values obtained by different analysis method for skim milk powder at different moisture contents. (Ref: P. Boonyai et al., 2007)

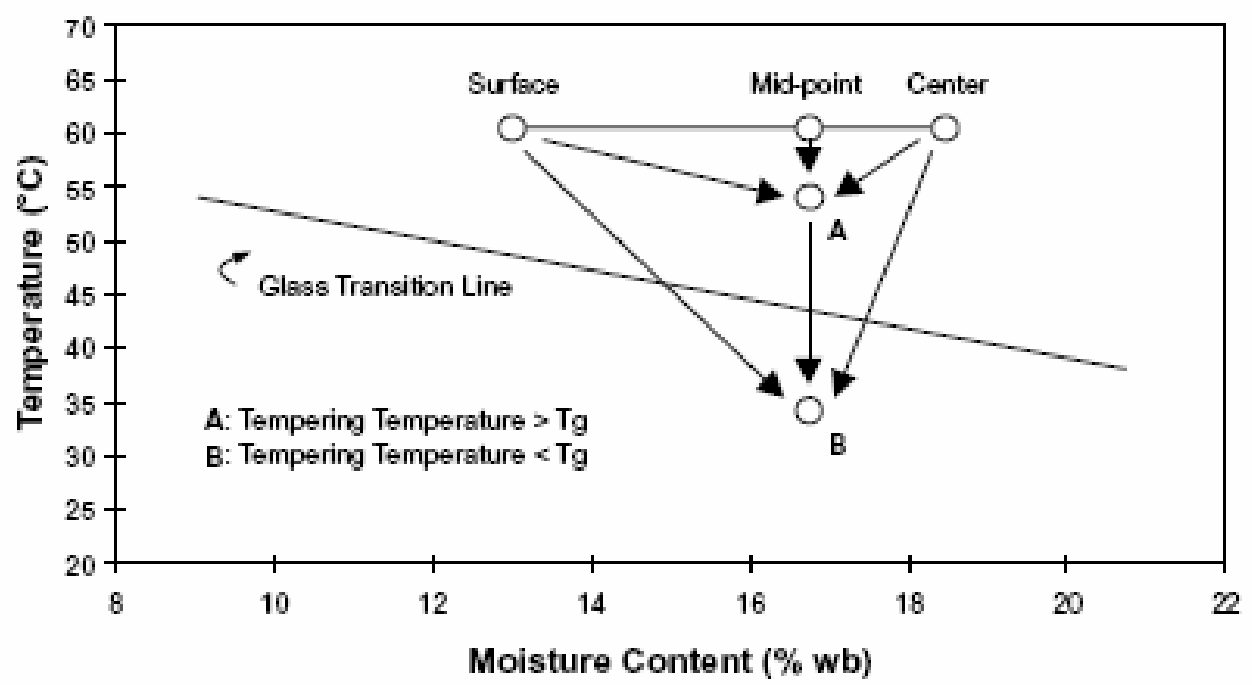

Figure 11. Moisture content gradient inside a rice kernel at the end of drying and a hypothetical response of the various sections of a kernel during tempering for two tempering scenarios. The glass transition line represents the temperatures at which the rice transitions from a glassy (below $\mathrm{Tg}$ ) to a rubbery state (above $\mathrm{Tg}$ ) or vice versa. Surface, midpoint, and center refer to the surface, mid-point between the surface and the center, and the center of a rice kernel (Ref: A.G. Cnossen et al., 2003) 


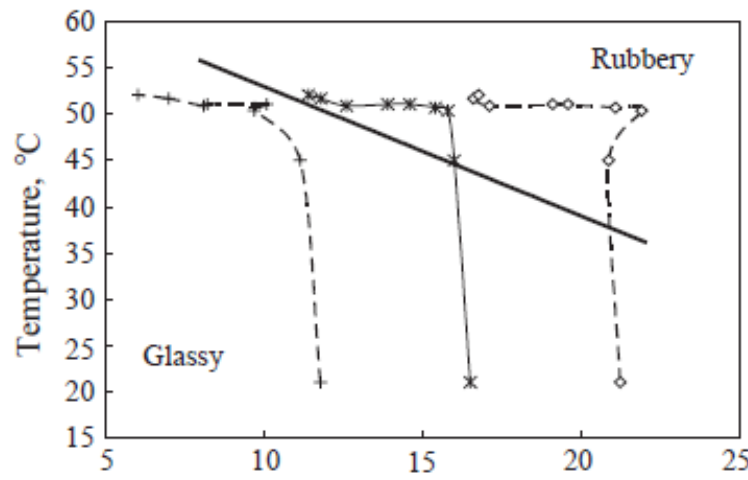

(a)

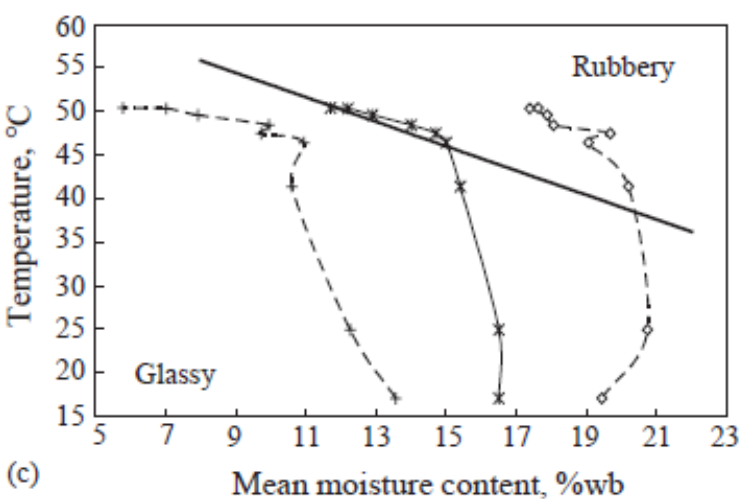

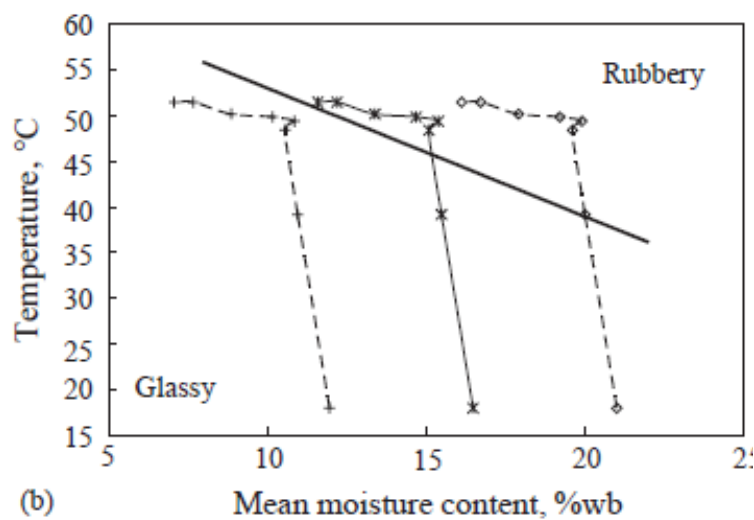

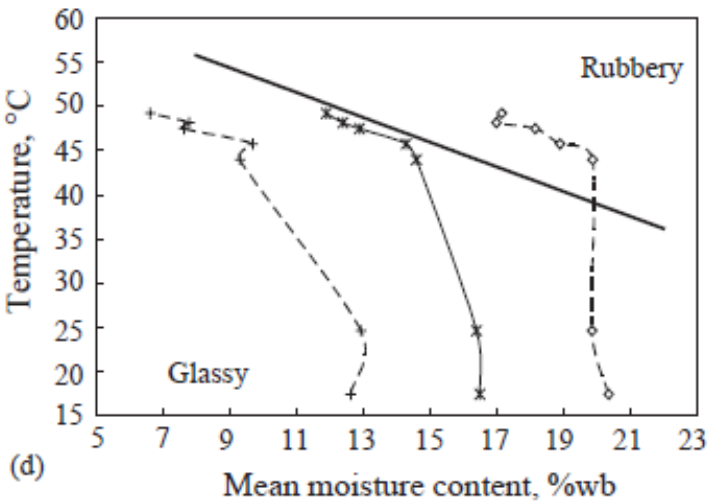

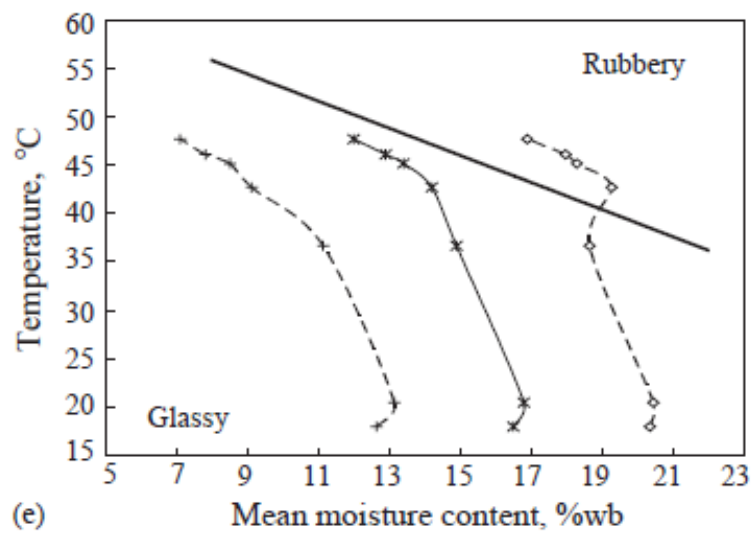

Figure 12. Drying behaviour of Bengal rice kernels at five locations depicted on the rice glass transition state diagram; MC, mean moisture content of 300 kernels; MC+ and MC-, upper and lower $95 \%$ confidence limits of kernel moisture contents, respectively; Tg, statistical trend line of the glass transition temperatures measured by differential scanning calorimeter; - Tg; -* - , MC; -- ---, MC+; -----, MC-. (a) location 1 (2.5 cm from air inlet); (b) location 2 (7.6 cm from air inlet); (c) location 3 (15.2 cm from air inlet); (d) location 4 (22.9 cm from air inlet); (e) location 5 (30.5 cm from air inlet). (Ref: W. Yang et al., 2003) 


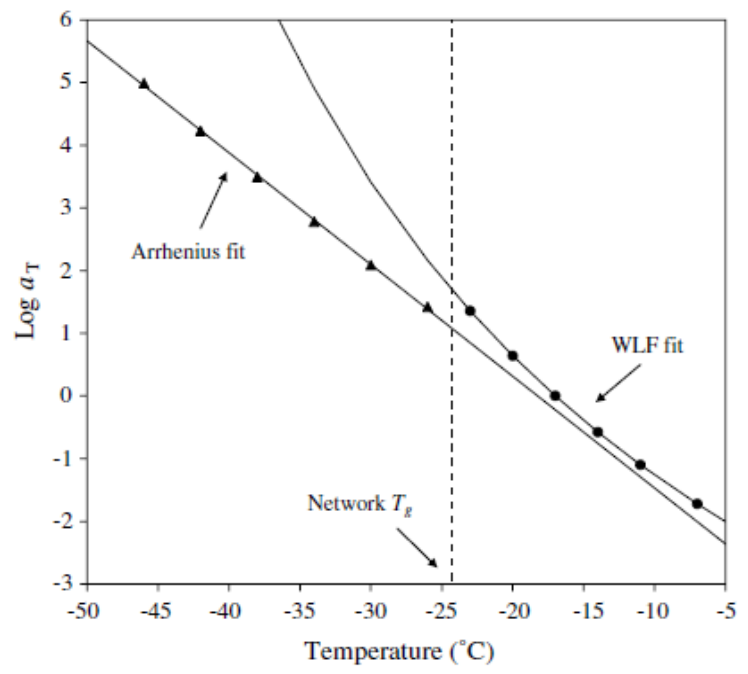

Figure 13. Temperature variation of the factor $\mathrm{a}_{\mathrm{T}}$ for the glass transition region $(\bullet)$ and the glassy state $(\mathbf{\Delta})$. The solid lines reflect the WLF fit in the glass transition region, and the modified Arrhenius fits in the glassy state. The dashed line pinpoints the prediction of the network glass transition temperature. (Ref: Stefan Kasapis et al., 2008)

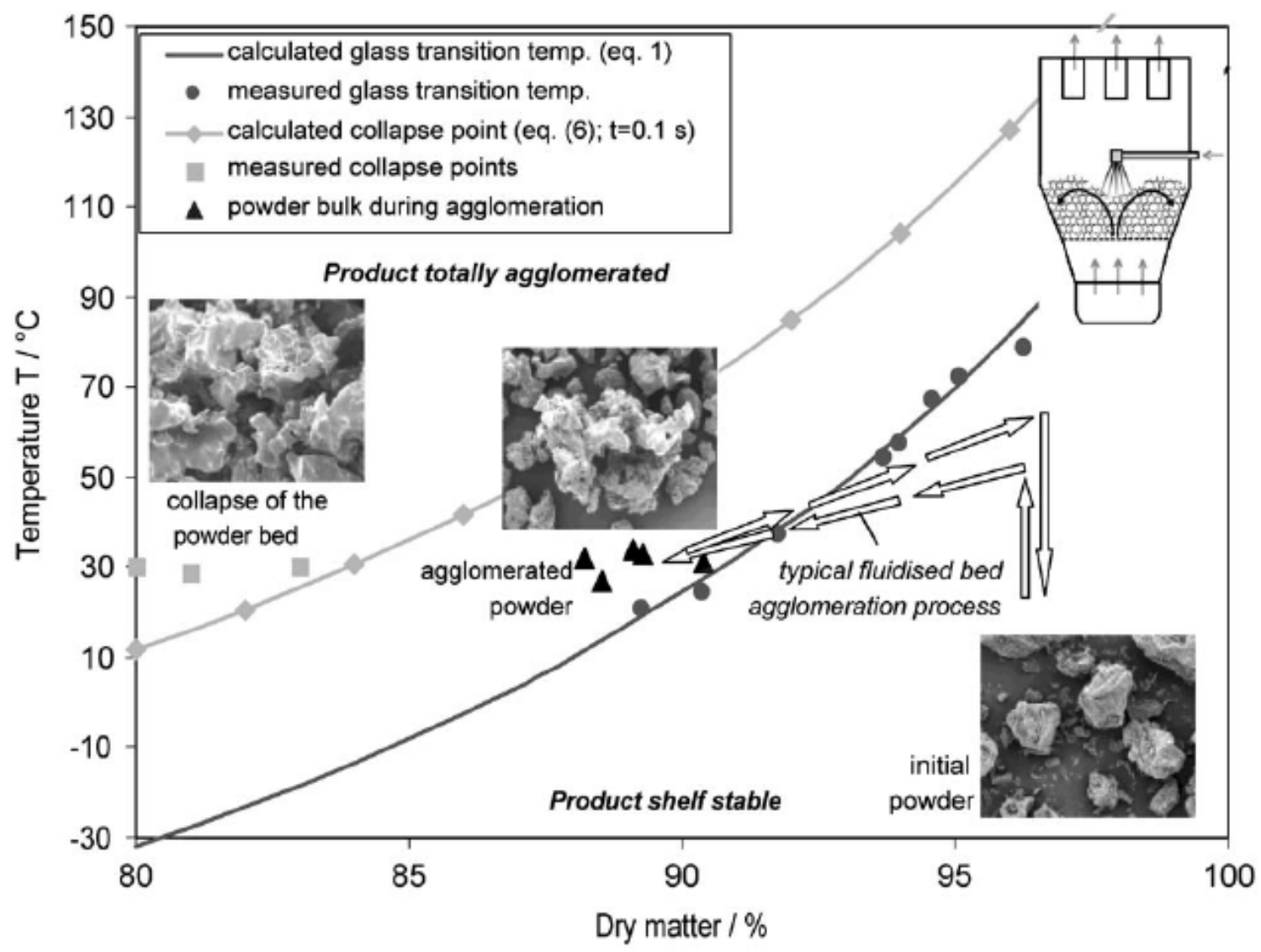

Figure 14. Visualisation of fluidised bed agglomeration in the moisture/temperature diagram.

(Ref: Stefan Palzer, 2005) 


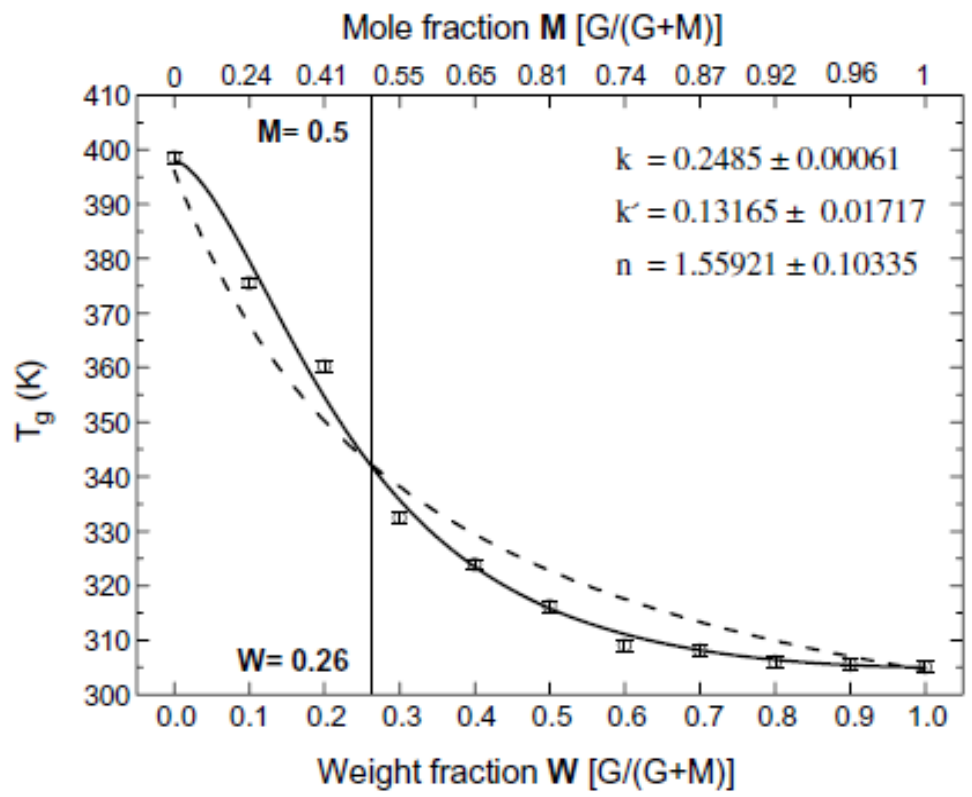

Figure 15. Glass transition temperatures of monosaccharide-trisaccharide (glucose-maltotriose) mixtures as a function of weight fraction and mole fraction. The dashed lines are fitted results using the Gordon-Taylor equation and the solid lines are fitted results using the modified Gordon-Taylor equation. In this figure, G represents glucose and $\mathrm{M}$ represents maltotriose. (Ref: Jeong-Ah Seo et al., 2006)

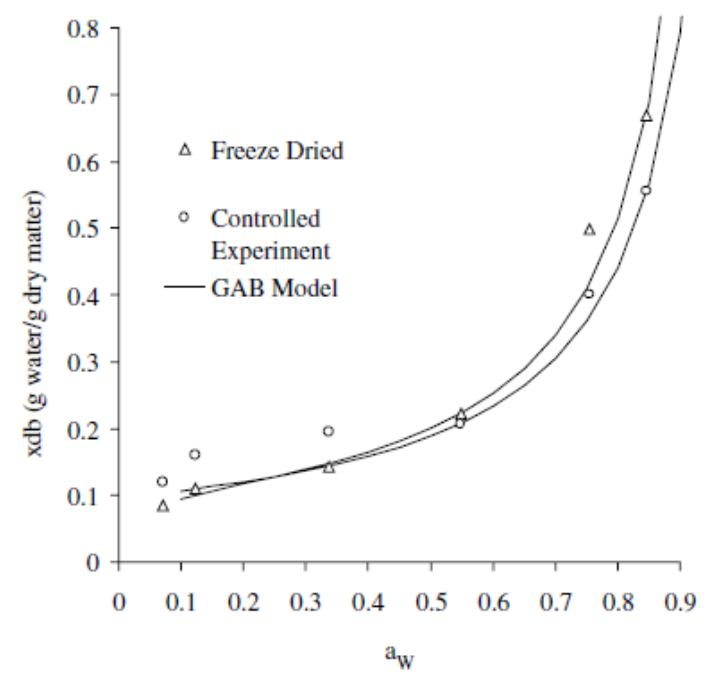

Figure 16. Water sorption isotherms of freeze dried and control date paste at $20{ }^{\circ} \mathrm{C}$.

(Ref: Jasim Ahmed et al., 2005) 


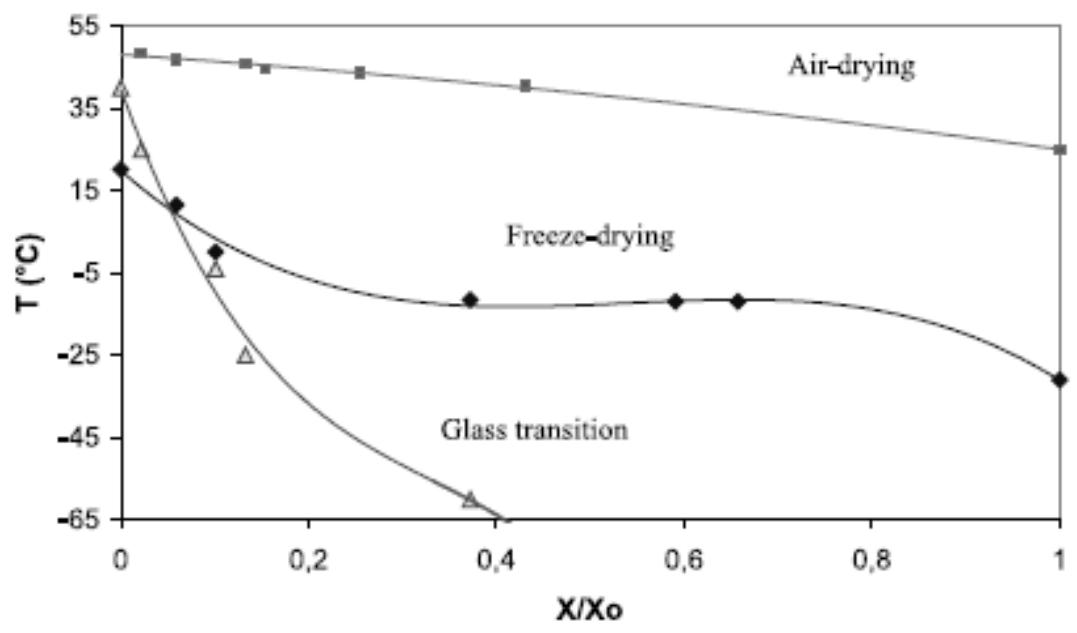

Figure 17. Progression of temperatures during drying $\left(\right.$ at $\left.50^{\circ} \mathrm{C}\right)$ and freeze drying $\left(\right.$ at $\left.20^{\circ} \mathrm{C}\right)$ of strawberries as compared to its glass transition temperatures. (Ref: C. Ratti, 2001)

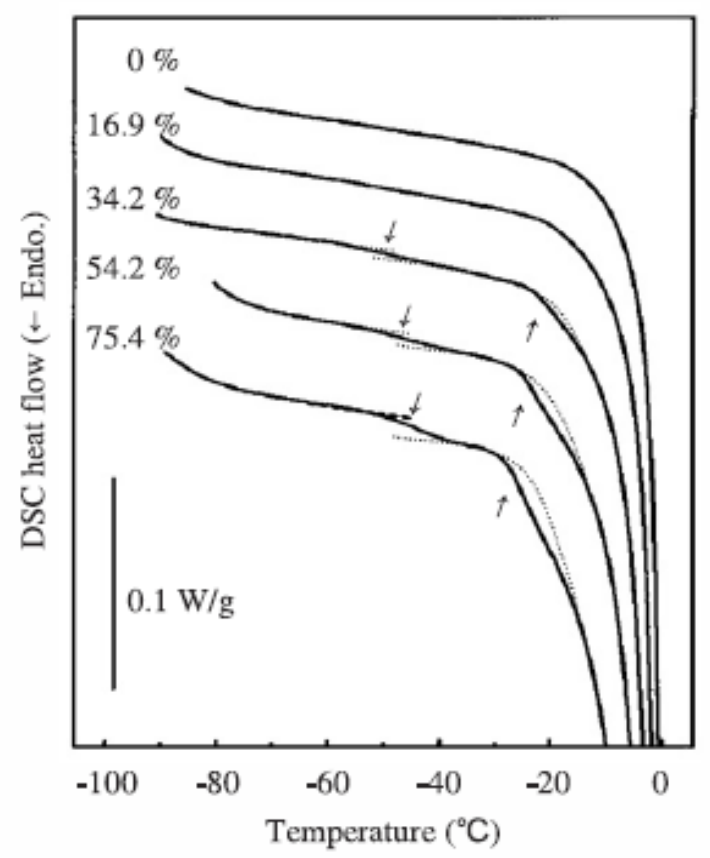

Figure 18. DSC thermograms for carp surimi-trehalose mixtures of varying trehalose content. Down-arrows, up-arrows, and dotted lines indicate T'g1, T'g2, and expected baseline, respectively.

(Ref: Chisato Ohkuma et al., 2008) 